\title{
Terapia ocupacional: uma profissão feminina ou feminista?
}

\author{
Occupational therapy: a feminine or feminist profession?
}

Elizabeth Maria Freire de Araújo Lima1

DOI: 10.1590/0103-11042021E112

RESUMO Considerando que a maioria das terapeutas ocupacionais são mulheres e que a profissão foi pensada, em seu início, como uma profissão feminina, este ensaio recuperou a presença do movimento feminista no solo em que germinou a terapia ocupacional e suas possíveis contribuições para o desenvolvimento da profissão na atualidade. $O$ texto foi construído a partir de um estudo teórico, histórico e crítico, que revisitou as origens da terapia ocupacional enquanto campo de práticas e saberes ligados ao cuidado para apresentar exercícios para uma genealogia da profissão, enfatizando a presença, em seu surgimento, nos Estados Unidos da América, no início do século XX, do ativismo político e do pensamento feminista. Dessa forma, buscou-se problematizar os contornos tradicionalmente impostos à profissão e reativar a dimensão ético-política que marcou fortemente sua emergência, questionando as desigualdades de gênero que a atravessaram ao longo desses pouco mais de 100 anos de existência. A aproximação de epistemologias feministas foi fundamental para a realização desse percurso, que buscou dar visibilidade à potência da terapia ocupacional para escapar às modelagens restritivas da vida e do trabalho no contemporâneo.

PALAVRAS-CHAVE Terapia ocupacional. Feminismo. Profissões em saúde.

\begin{abstract}
Considering that most occupational therapists are women, and that the profession was initially thought of as a women's profession, this essay restores the presence of the feminist movement in the soil in which occupational therapy germinated and its possible contributions to the development of the profession today. The essay is based on a theoretical, historical, and critical study that revisits the origins of occupational therapy as a field of practices and knowledge related to care, to present exercises for a genealogy of occupational therapy, emphasizing the presence of political activism and feminist thought in the emergence of the profession in the United States of America in the early 20th century. In this way, we aimed to problematize the contours traditionally imposed on the profession and reactivate the ethical-political dimension that strongly marked its emergence by questioning the gender inequalities that permeated the profession during these little more than 100 years of existence. The approach of feminist epistemology was fundamental to this path, which sought to give visibility to the potency of occupational therapy to escape the restrictive models of life and work in the contemporary world.
\end{abstract}

KEYWORDS Occupational therapy. Feminism. Health occupations. 


\section{Introdução}

Não foi por acaso que, no início do século XX, nos Estados Unidos da América (EUA), surgiu a terapia ocupacional. A I Grande Guerra originou um contingente excepcional de pessoas com severas limitações para viver e realizar suas atividades cotidianas. Ficou a cargo de mulheres a tarefa de cuidar desse contingente populacional, majoritariamente masculino, recuperar sua capacidade e prepará-lo para o retorno ao trabalho. Elas eram as profissionais da reconstrução'.

Assim, apareceu uma profissão extemporânea. Não porque esteja à frente do seu tempo, mas, porque surgiu pautada no humanismo, voltada para a reparação de seres humanos e de sua capacidade para o trabalho, em um século em que o trabalho humano se tornou cada vez mais supérfluo e a própria ideia moderna de homem começou a desaparecer do horizonte. Com a financeirização da economia e a instauração do capitalismo cognitivo, o capital passou a ser gerado pela própria acumulação de capital, em conjunção com a exploração dos cérebros em cooperação ${ }^{2}$, e o trabalho deixou de ser a principal força produtora de riqueza. Nesse contexto, o contingente de excluídos só aumentou, culminando com a produção de um número incalculável de pessoas que peregrinavam sem um lugar - refugiados, povos autóctones destituídos de suas terras, grupos sem terra, sem teto -, pessoas cujas vidas foram marcadas pela luta pela sobrevivência, e que, ao longo do século, foram sendo confinadas e tratadas como vidas supérfluas ${ }^{3}$, que, não sendo passíveis de luto ${ }^{4}$, tornaram-se vidas matáveis 5 .

As filosofias e racionalidades que sustentam e atravessam a terapia ocupacional têm uma longa história. Autores do campo, no Brasil e no exterior, referem-se a diversos povos da Antiguidade, como gregos, egípcios e persas, para os quais o engajamento em atividades teria um papel fundamental na saúde e no bem-estar6,7. De alguma forma, essa herança põe a área de saberes e práticas da terapia ocupacional em descompasso com o tempo em que surge, seja em relação ao modo de produção capitalista; seja em relação à perspectiva positivista que dominava a ciência da época. Outrossim, talvez seja esse mesmo elemento de descompasso que torne possível, a partir de suas lentes, enxergar outros mundos e outras formas de vida ainda por vir.

No entanto, por emergir como profissão, no início do século XX, as linhas de constituição da modernidade e os acontecimentos desse século tiveram uma importância crucial para esse surgimento e para as formas que a terapia ocupacional foi ganhando ao longo dos anos que se seguiram.

Este ensaio, construído a partir de um estudo teórico, histórico e crítico, buscou problematizar as origens da terapia ocupacional enquanto campo de práticas e saberes ligados ao cuidado, apresentando alguns elementos para uma genealogia ${ }^{8}$ da profissão: o tratamento moral, a industrialização, o Movimento de Artes e Ofícios, a filosofia pragmatista e o feminis$\mathrm{mo}^{7}$. Nas páginas que se seguem, revisitaremos brevemente esses elementos, a forma como impactaram o surgimento da profissão e como foram sendo obscurecidos com sua institucionalização. Em especial, daremos atenção às forças que convergiram para que a profissão fosse identificada como uma profissão adequada para as mulheres ${ }^{9-11} \mathrm{e}$ à presença do ativismo político e do pensamento feminista no solo em que germinou a terapia ocupacional e a sua recuperação na atualidade atualidade ${ }^{12-14}$. Dessa forma, buscamos reativar a dimensão ético-política que marcou fortemente a emergência da profissão e problematizar as desigualdades de gênero que a atravessaram ao longo desses pouco mais de 100 anos de existência.

\section{Exercícios de genealogia: a emergência de um campo de saberes e práticas}

O tratamento moral evidencia o forte liame entre terapia ocupacional e disciplina. Para William Tuke, o trabalho teria um poder de 
constrangimento maior que todas as formas de coerção; e, no tratamento de doentes mentais, um trabalho regular seria a mais eficaz entre todas as formas de induzir o paciente a conter-se a si mesmo ${ }^{7(168)}$.

No entanto, além do tratamento moral, no solo em que emergiu a terapia ocupacional, estavam presentes elementos relacionados com perspectivas filosóficas e com práticas políticas, que tiveram um importante papel no surgimento da profissão, como o Movimento de Artes e Ofícios, o pensamento pragmatista e o movimento feminista ${ }^{7,15}$. Esses elementos situam a terapia ocupacional no seu tempo, paradoxalmente em desencaixe e em luta contra as forças hegemônicas desse tempo, por sua associação a ideias e movimentos que confrontam a forma de vida moderna ocidental e o modo de produção capitalista.

Esses elementos se encontraram em uma experiência acontecida em Chicago, em um assentamento urbano em que jovens mulheres, em sua maioria provenientes das classes médias, viveram juntas sob princípios colaborativos, na busca por enfrentar os problemas sociais, econômicos e de saúde dos imigrantes e outras comunidades minoritárias privadas de direitos. Essas mulheres estavam ligadas ao movimento feminista nos seus primeiros anos, lutavam pelo sufrágio universal, procuravam uma profissão e uma forma de atuação na esfera pública, e se encontraram em uma experiência que marcaria fortemente a terapia ocupacional.

$\mathrm{Na}$ época - quando imigrantes chegavam em grande número aos EUA, vindos de regiões empobrecidas e trazendo culturas e hábitos estranhos -, a ideia corrente era a de que o crescimento urbano, o trabalho feminino e a imigração traziam degeneração social e favoreciam a propagação de doenças. Por isso, muitos imigrantes eram levados a viver em condições deploráveis ou em locais de internamento. Foi nesse contexto que, em 1889, duas ativistas socialistas, Jane Addams e Ellen Gates Starr, fundaram a Hull House, o mais importante e influente assentamento social para imigrantes nos EUA, que rapidamente se tornou uma incubadora de programas sociais ${ }^{16}$.

Situada em uma região de Chicago densamente povoada por imigrantes judeus, italianos, irlandeses, alemães, gregos, russos e poloneses, aos quais vieram se juntar, durante a década de 1920, africanos e mexicanos, a Hull House, no início do século XX, compreendia um complexo de 13 edificações em uma estrutura que incluía ginásio, teatro, galeria de arte, biblioteca, escola de música, ateliês, cozinha, cafeteria, residência cooperativa para mulheres trabalhadoras, clínica, berçário, jardim de infância, espaço de encontro para sindicatos e apartamento para moradia da equipe responsável. Esse complexo se tornou um centro cultural com ofertas musicais e teatrais, além de espaço para programas sociais, educacionais e artísticos, em que os moradores do bairro, imigrantes de diversas origens, reuniam-se para conviver, comer, estudar, debater, e no qual encontravam suporte, assistência e ferramentas necessárias para viver no novo país ${ }^{17}$.

Wilcock cita em seu livro um trecho em que Jane Addams descreve esse assentamento:

Um esforço experimental para ajudar na solução dos problemas sociais e industriais que são engendrados pelas condições de vida em uma grande cidade... É uma tentativa de atenuar a disparidade entre a superacumulação em um dos extremos da sociedade e os destituídos no outro [tradução nossa $]^{7(175) \text {. }}$

Os moradores do assentamento eram famílias de trabalhadores de baixa renda e pessoas que escolhiam viver na Hull House. Juntamente com os frequentadores, elaboravam e desenvolviam atividades, de forma que a convivência e o intercâmbio cultural fossem favorecidos. Nas duas primeiras décadas do século XX, esse grupo de pessoas se envolveu nas lutas pela criação de políticas públicas relacionadas com educação, saúde, moradia, trabalho e condições sanitárias, pelo estabelecimento de legislações protetivas para mulheres e crianças, e de leis relativas à segurança 
e saúde no trabalho, à educação obrigatória, proteção dos imigrantes e ao sufrágio feminino.

Assim, o trabalho desenvolvido na Hull House foi responsável por expandir a participação social das mulheres em diferentes campos e consolidar sua força política. Ao iniciar uma prática profissional de cuidado, essas mulheres se encontravam em situação próxima à daquelas pessoas com quem iriam trabalhar, pela falta de oportunidade de emprego, pela restrição de sua participação no espaço público e pelo impedimento do exercício da ação política - o que Wilcock denomina de privação ocupacional ${ }^{7}$.

Uma importante colaboradora desse experimento social, Julia Lathrop, criou, em 1908, um curso para atendentes de hospitais psiquiátricos sobre Ocupação e Recreação Curativa, que incluía um treinamento prático em terapia ocupacional e palestras sobre doença mental e seu tratamento. Outra colaboradora da Hull House foi Eleanor Clarke Slagle, frequentemente apontada como a fundadora da terapia ocupacional. Profundamente interessada nos problemas sociais e nas mudanças em curso no País naquele momento, Slagle separou-se do marido e decidiu se juntar aos reformadores sociais, mudando-se para Chicago em 1911, onde frequentou o Curso de Ocupação e Recreação Curativa. Logo depois, passou a ministrar cursos semelhantes em instituições psiquiátricas. Sua ligação com o psiquiatra Adolf Meyer gerou as bases para a criação da nova profissão. Meyer propunha uma visão inovadora da doença mental e seu tratamento, defendendo a manutenção dos pacientes em sua comunidade; acreditava que as experiências da vida tinham um importante papel na etiologia das doenças mentais e sustentava que o tratamento deveria buscar, por meio de ocupações terapêuticas, o desenvolvimento de habilidades e recursos que permitissem aos pacientes conviver e participar da vida social. Acompanhando as ideias pragmatistas, o psiquiatra professava, segundo Wilcock ${ }^{7(179)}$, que "fazer, ação e experiência é ser" e que "atividades expressas no viver demonstram a síntese mente-corpo".
A Hull House foi também um centro em que temas do pragmatismo e ideias do Movimento de Artes e Ofícios foram experimentados ${ }^{\mathbf{1 8 , 1 9}}$. Esse movimento surgiu na segunda metade do século XIX, na Inglaterra, em meio à Revolução Industrial, quando a industrialização crescente e a mecanização do trabalho transformavam o modo de produção e o cotidiano dos trabalhadores e criavam outra realidade, marcada pela produção em massa e pela sociedade de consumo. Com raízes no Romantismo e no socialismo utópico, esse movimento estético buscava se opor às rápidas mudanças nos modos de produção, defendendo a participação da criatividade no trabalho artesanal e a superação da distinção entre o artesão e o artista. $\mathrm{O}$ movimento propunha, também, um retorno à vida simples, na qual corpo e mente pudessem estar engajados em um trabalho significativo, relevante, que tivesse sentido para quem faz e sua comunidade ${ }^{19}$.

Por sua vez, as ideias pragmatistas de William James e John Dewey influenciaram fortemente Adolph Meyer e foram centrais para o trabalho de Slagle. Caracterizado por um empirismo radical, com a atenção voltada para os feitos concretos e a vida cotidiana, o pragmatismo postula que as ações constituem o eixo em que se sustenta a atividade interpretativa que caracteriza o conhecimento. $\mathrm{O}$ pensamento provém, portanto, da experiência, e o processo de conhecimento está vinculado ao que a pessoa faz, influindo, ao mesmo tempo, sobre o que ela pode ou quer fazer. Para William James, pensamento e ação se entrelaçam no fluxo ininterrupto da experiência, constituindo uma consciência incorporada, ativa, que revela um todo complexo, orgânico, que se move em um determinado ambiente. Toda atitude consciente é já um agir no ambiente no qual o corpo está imerso ${ }^{20}$. John Dewey, que trabalhou na Universidade de Chicago e dedicou-se à educação e reconstrução social, exerceu também grande influência na terapia ocupacional. Considerava que o conhecimento resultava de experiências e acreditava que as atividades eram formas de 
intervir e alterar a aprendizagem e a saúde 7 .

Em 1917, reuniram-se para fundar a American National Society for the Promotion of Occupational Therapy, além da trabalhadora social Eleonor Clark Slagle, os arquitetos George Edward Barton e Thomas Bessell Kidner, o médico William Rush Dunton e a professora de artes e ofícios Susan Cox Johnson ${ }^{7}$. Nutrido pelas ideias do pragmatismo e tocado pelo Movimento de Artes e Ofício, esse grupo de fundadoras e fundadores da terapia ocupacional, embora bastante heterogêneo, considerava a relevância da ação para a vida humana e compartilhava a concepção de que a realização de atividades favoreceria o desenvolvimento, a saúde e a participação social e poderia ajudar pessoas que se encontrassem alijadas dessa participação, em situações de sofrimento ou de adoecimento.

\section{Exercícios de genealogia: a institucionalização da profissão na área da saúde}

A institucionalização da terapia ocupacional como profissão se deu em uma América do Norte que se desenvolvia rapidamente; e, com ela, o modo de produção capitalista. Nesse percurso, um campo emergente de práticas e saberes - que vinha se constituindo em uma forte conexão com as lutas pelos direitos de todas as pessoas, problematizando a forma que o trabalho ganhava com a industrialização e os processos de exclusão que marcavam aqueles que não estavam aptos a participar do mercado de trabalho -, ao buscar regulamentação e reconhecimento como profissão de saúde, subordinou-se ao saber e ao poder médico, e perdeu sua marca política e ativista.

Em 1917, no momento de sua fundação oficial, com a criação da American National Society for the Promotion of Occupational Therapy, a terapia ocupacional se vinculou ao Exército Americano e à Associação Médica Americana - duas das instituições mais poderosas e conservadoras do País ${ }^{\mathbf{1 5}}$. Nesse mesmo ano, os EUA entravam na I Guerra Mundial, o que teve como consequência um aumento do número de pessoas com lesões graves e o desenvolvimento de técnicas médicas e cirúrgicas, que foram acompanhados por uma formação voltada para reabilitação e reorientação profissional21.

Assim, a terapia ocupacional, que surgiu banhada em perspectivas humanistas e socialistas, abandonaria suas raízes ativistas, sua ligação com o feminismo e sua perspectiva filosófica para ligar-se a perspectivas individualistas nos anos que se seguiram, de forma que foi enfraquecida uma abordagem crítica que considerasse a exploração em jogo no trabalho industrial, no interior do capitalismo.

Além disso, a profissionalização no campo da saúde, de uma prática que originalmente continha elementos da educação, das artes e do trabalho social, subordinou os saberes da terapia ocupacional ao conhecimento médico e exigiu um esforço por parte das terapeutas ocupacionais no sentido de aumentar sua credibilidade e ganhar reconhecimento, mediante o investimento em conteúdos e formas de fazer considerados científicos, o que teve um forte efeito limitador?

A relação de poder desigual que se estabeleceu impactou decisivamente o desenvolvimento da profissão e determinou sua mudança de foco. A literatura dos primeiros anos era predominantemente médica e buscava explicar cientificamente os efeitos das atividades no organismo dos indivíduos. Como as perspectivas filosóficas presentes no surgimento da profissão não puderam ser articuladas aos modelos científicos vigentes de modo a formar uma síntese coerente, foram, aos poucos, sendo obscurecidas e abandonadas, e os programas de formação em terapia ocupacional passaram a ter um caráter eminentemente técnico.

A profissão nascente foi, assim, submetida a uma pressão em direção ao reducionismo e ao modelo biomédico, o que levou ao desenvolvimento de uma reabilitação cuja finalidade seria a adequação das pessoas atendidas a um 
padrão de normalidade, ignorando as singularidades das vidas e suas potências. Em pouco tempo, a efervescência dos primeiros anos foi capturada e silenciada.

A tentativa de tornar a terapia ocupacional científica estava relacionada com uma busca por reconhecimento e investimento para a área. Afinal, quanto mais científico um campo de práticas e saberes se torna, mais status e reconhecimento recebe, e mais facilmente obtém financiamento. Essa era, ao menos, a crença das profissionais. No entanto, embora fossem pressionadas a justificar a sua atuação por meio de um conhecimento baseado em evidências, essas profissionais eram confrontadas frequentemente com impedimentos para o desenvolvimento de suas carreiras e com uma falta crônica de investimento em formação e preparação de pesquisadores, o que minava todos os esforços ${ }^{22}$.

Nesse processo, a base intelectual e filosófica da terapia ocupacional perdeu seu lugar de destaque na formação e foi abandonada, em favor de um treinamento técnico, o que inibiu, por muito tempo, a invenção de formas de produzir conhecimento que pudessem acolher a singularidade do campo; o que finalmente está podendo acontecer, quando a profissão busca sua legitimação em outras bases.

Embora a perspectiva desenvolvida na Hull House e sua radicalidade política tenham permanecido à margem do mainstream $\mathrm{da}$ profissão na Europa e nos EUA, Gelya Frank e Ruth Zemke consideram que ela constitui um precedente para o engajamento político e a busca por transformações sociais no campo ${ }^{15}$.

As linhas de força que marcaram a aventura política, teórica, ética, estéticas e clínica na Hull House, em Chicago, permaneceram vivas no solo da terapia ocupacional. Nessa experiência, podemos encontrar mitos fundadores que podem servir para a construção do que Daniela $\mathrm{Melo}^{\mathbf{2 3}}$ chama do ethos da profissão. Constrói-se, assim, para as terapeutas ocupacionais, a imagem de mulheres que desafiam seu tempo e recusam o lugar que lhes foi designado, introduzindo-se na arena pública.

As feministas e as socialistas do início do século, nos EUA, não lutaram somente pelos seus próprios direitos: ao enfrentarem a condição de privação de direitos em que se encontravam, perceberam um plano comum com muitas outras pessoas que compartilhavam a mesma condição. Em uma experiência de horizontalidade, foram viver com imigrantes assentados, e transformaram um lugar de exclusão em espaço de encontro, convivência, formação, fruição e produção cultural. Assim, fizeram do espaço de exclusão e ocultamento um espaço público, no qual a vida política podia ter lugar.

Para pensar e estudar um modo de fazer terapia ocupacional que reative essa herança, é necessário se aproximar de outras formas de fazer ciência e de frutificar os saberes.

\section{Epistemologias feministas: abrindo outras perspectivas para a produção de conhecimento}

O pensamento feminista, o feminismo negro e as pesquisas acadêmicas e ativistas informadas por essas vertentes teóricas têm produzido uma crítica contundente à ciência contemporânea, ao identificar, na estrutura do modo de conhecimento que predomina nos espaços ocidentais do conhecimento, a manutenção da figura do homem branco e de sua intenção de tudo conhecer e controlar.

As críticas feministas salientam que a visão ocidental do mundo e sua ciência, como vêm se desenvolvendo desde o período iluminista, estão fortemente marcadas por condições políticas, econômicas e sociais de ordem patriarcal, o que excluiu por muito tempo as mulheres do fazer científico e das atividades intelectuais. Essas críticas levantam questões epistemológicas e éticas, além de problematizar as experiências das mulheres em ambientes acadêmicos e científicos, nos quais, com frequência, sentem-se desqualificadas em seus próprios campos de especialização e 
se colocam em conflito em relação às formas de interação e às práticas que aí operam²4.

Diferentes correntes feministas, em particular o feminismo negro, têm apontado que a forma hegemônica de fazer ciência corresponde a uma forma específica de ser e de agir no mundo. Patricia Hill Collins afirma que muitas mulheres afro-americanas compreenderam uma conexão entre o que alguém faz e como alguém pensa, chamando nossa atenção para a forma como as variações nas experiências de homens e mulheres levam a diferenças de perspectiva - e, é claro, essas diferentes perspectivas, que emergem de grupos com poderes diferentes, não têm o mesmo valor nas academias e instituições científicas. Grupos desiguais em termos de poder são, consequentemente, desiguais em seu acesso aos recursos necessários para implementar suas perspectivas fora de seu grupo particular, o que faz com que essas sejam desacreditadas e suprimidas 25 .

Ainda assim, a crítica feminista não quer estabelecer uma cruzada contra os saberes e a ciência. As ciências naturais, sociais e humanas são lugares de produção de mundos e podem constituir modos de vida e ordens sociais mais cooperativas e formas de enfrentamento de problemas coletivos. Se a ciência reproduz em seu interior desigualdades e relações de opressão, isso faz surgir a necessidade de pensar e propor formas de gerar e validar conhecimento em outras bases, que não sejam redutíveis aos jogos de poder ou à arrogância cientificista.

É importante lembrar que não há um ponto de vista feminista único, já que pontos de vista são enraizados em condições reais e materiais concretas ${ }^{25}$. Todavia, talvez seja possível, tranversalizando os diferentes pontos de vistas de mulheres, encontrar um comum nas proposições feministas: uma ética e uma política de epistemologias localizadas, limitadas, situadas, corporificadas e responsáveis, que recuperem a ligação entre o pensamento e a vida.

As feministas querem reforçar a parcialidade das afirmações científicas, sua contingência e sua dependência de acontecimentos concretos; argumentam, assim, em favor de uma prática científica que privilegie o diálogo, a contestação e as conexões em rede para que seja possível transformar os sistemas de conhecimento e as maneiras de viver.

Nesse contexto, Haraway ${ }^{\mathbf{2 6}}$ propõe um projeto de ciência que possa insistir na diferença irredutível e na multiplicidade radical dos conhecimentos locais, produzidos a partir de corpos enraizados em situações específicas. Saberes localizados implicam também levar em consideração a agência daquilo que será estudado. $\mathrm{O}$ mundo encontrado nos empreendimentos de pesquisa torna-se uma entidade ativa, na medida em que uma prática científica seja capaz de se relacionar, de fato, com ele.

Não estamos no comando do mundo, diz Haraway 27(31), apenas vivemos aqui como mortais, e tentamos estabelecer conversas com os que vivem conosco. Estamos em meio a uma multiplicidade de existências conectadas e em relação:

Aqui um animal, ali uma criança doente, uma aldeia, rebanhos, laboratórios, bairros numa cidade, indústrias e economias, ecologias que ligam naturezas e culturas sem fim.

Pesquisar é estar em meio a relações com coisas e seres que importam e que exigem resposta. A capacidade de responder é a capacidade de se responsabilizar por aquilo que se faz no interior dessas relações.

Já nos anos 1980, Patricia Hill Collins ${ }^{25}$ afirmava que epistemologias alternativas desafiam os conhecimentos certificados e abrem a questão de saber se o que foi tomado como verdadeiro pode resistir ao teste de maneiras alternativas de validar conhecimentos. A existência de pontos de vista independentes de mulheres brancas, de mulheres negras, de mulheres cis, de mulheres trans, de tantas outras formas de experimentar os desencaixes e desajustes em relação à forma hegemônica de ser, de pensar e de fazer ciência faz emergir múltiplas epistemologias feminista, põe em questão o conteúdo do que se entende por verdade e desafia simultaneamente o processo de chegar a essa verdade. 


\section{Ciência, feminismo, pensamento e terapia ocupacional}

Em 2010, na conferência de encerramento do Congresso da Federação Mundial de Terapeutas Ocupacionais, o primeiro a acontecer no Hemisfério Sul, Sandra Galheigo ${ }^{\mathbf{2 8}(60)}$ falou sobre uma geração de terapeutas ocupacionais que, nos anos 1980, no Brasil e na América Latina, trabalhando com pessoas excluídas do acesso aos direitos, decidiu buscar respostas e teorias que pudessem explicar o "verdadeiro problema dos problemas sociais". Colocava-se, para os profissionais, a necessidade de compreender as relações complexas que ligam os sofrimentos das pessoas atendidas em terapia ocupacional ao contexto político, econômico e social. Assim, terapeutas ocupacionais se acercaram de assuntos como a influência da estrutura social, ideologia, cultura, microfísica do poder, disciplina e controle social, ao mesmo tempo que se aproximaram das pessoas para escutar suas histórias e lutas, e aprender com elas.

As décadas de 1980 e 1990 representaram um ponto de virada na constituição de uma terapia ocupacional brasileira, tanto na prática profissional quanto na construção e compartilhamento de saberes e formação de novos terapeutas. A participação nas lutas pela redemocratização e por direitos para todos; a produção de teorias e metodologias locais; o surgimento das primeiras revistas na área; o trabalho em equipes interdisciplinares e a formação em nível de pós-graduação em diferentes campos de saber, incluindo as artes e humanidades, foram decisivos para fortalecer uma perspectiva crítica no seio da profissão. Nesse contexto, houve uma ampliação do debate crítico no campo, articulado à produção de uma cultura de resistência que se fazia na participação em diversos movimentos sociais, no diálogo com a música, o teatro, a literatura e as artes e no estudo de pensadores e pensadoras críticas.
Nesse processo, a atuação nas áreas de saúde, educação, cultura, trabalho e assistência social foram transversalizadas, trazendo uma perspectiva ético-estético-política para o campo. Uma abordagem ética articula-se necessariamente a uma posição política, quando conhecimentos e práticas estão comprometidos com a melhoria das condições de vida em um sentido amplo; e é necessariamente estética porque compreende uma dimensão de criação de práticas, pensamentos e formas de relação. Isso indica também a necessidade de adoção de novas abordagens metodológicas e epistemológicas.

A introdução do enfoque feminista em pesquisas no campo e a retomada da reflexão filosófica têm: ressaltado a importância dessas articulações; possibilitado o questionamento do modelo científico que foi imposto ao campo; e contribuído para problematizar as relações de poder pautadas nas desigualdades de gênero, que foram determinantes para a domesticação das forças revolucionárias presentes em sua germinação23. Dessa forma, tem sido possível reescrever a história da terapia ocupacional, evidenciando momentos de submetimento e opressão, e outros em que se afirma e potencializa sua forte marca feminina e feminista ${ }^{11,14}$.

Considerando que os lugares profissionais revelam exercícios e relações de poder, autoras como Gelya Frank ${ }^{\mathbf{1 2}}$, Ann Wilcock ${ }^{\mathbf{7}}$ e Daniela Melo ${ }^{23}$, entre outras, têm enfatizado o forte viés de gênero que marcou a divisão de trabalho no setor de saúde. Nessa perspectiva, a aceitação da subordinação à medicina por parte das primeiras terapeutas ocupacionais é compreendida como expressão da segregação de gênero que se fazia presente em todas as esferas da sociedade. Como em outras profissões da saúde subordinadas ao poder médico, a terapia ocupacional foi identificada, logo no início de sua institucionalização, como uma tarefa a ser realizada por mulheres, estabelecendo-se, portanto, como uma profissão feminina9-11,13.

No entanto, quais seriam as implicações de uma profissão ser vista como feminina? Para Sakelarious e Pollard, a identificação das 
profissionais aos estereótipos de gênero e a ausência, por muito tempo, de uma abordagem feminista e crítica dessa questão levaram a uma aceitação de funcionamentos e lógicas patriarcais, o que se expressou na tentativa de alianças com a medicina, mantendo as profissionais constrangidas em um mundo masculinamente ordenado, no qual princípios considerados femininos, como cuidar e nutrir, eram e são frequentemente desvalorizados ${ }^{\mathbf{2 2}}$.

Em um esforço em direção a uma profissionalização baseada em um modelo científico, médico e masculino, as primeiras terapeutas ocupacionais, como outras profissionais da saúde, aceitaram um papel subserviente nas estruturas dos serviços de saúde, que colocavam o homem em uma posição de poder, acreditando que, somente por meio da aliança com a medicina, a terapia ocupacional poderia alcançar o reconhecimento que merecia. Essa divisão de trabalho foi marcada também por uma distribuição desigual dos papéis na produção de conhecimento, que impactou fortemente a profissão. $\mathrm{O}$ fato é que, apesar de todo o esforço realizado, as terapeutas ocupacionais não conseguiram dar legitimidade científica à sua prática e às análises de atividade realizadas no campo nos termos de uma ciência biomédica. Segundo Sakelarious e Pollard ${ }^{22}$, o descompasso entre o saber-fazer das terapeutas ocupacionais e a produção em pesquisa continua sendo um problema da profissão, já que raramente se produz no campo um tipo de resultado que pode ser interpretado de forma generalizada, o que, muitas vezes, cria a percepção de que a complexidade da terapia ocupacional não poderia ser abordada em uma perspectiva científica.

Segundo Frank ${ }^{\mathbf{1 2}}$, isso permaneceu válido até recentemente, quando estudos feministas formularam um questionamento das práticas de pesquisa em saúde fundamentadas quase exclusivamente em uma visão médica e masculina do mundo, ao mesmo tempo que outras epistemologias começaram a ser introduzidas no campo, juntamente com a abordagem crítica das questões envolvidas na profissão.
Torna-se evidente que havia uma inadequação entre a forma de atuar, os problemas de que trata, os instrumentos e procedimentos da terapia ocupacional e a concepção de ciência à qual as terapeutas ocupacionais foram forçadas a buscar se adequar. Os conhecimentos que emergem do campo necessitam de outras epistemologias que afirmem a importância e o valor dos saberes localizados e corporificados.

Perspectivas críticas, epistemologias feministas e epistemologias do sul têm sido adotadas por terapeutas ocupacionais do Brasil e de outros países da América Latina, contribuindo para importantes avanços nas discussões dos referenciais filosóficos e epistemológicos da profissão, fortalecendo compromissos políticos e éticos dos profissionais com os direitos humanos e a justiça social. O crescente fortalecimento do pensamento crítico na América Latina corresponde a uma prática que tem sido desenvolvida em diálogo com as necessidades e contextos locais. Autores como Morán e Ulloa ${ }^{29(424)}$ propõem uma "perspectiva crítica em terapia ocupacional a partir da América Latina", afirmando a necessidade urgente de adotar uma atitude de "desobediência epistêmica", a qual implicaria tomar uma posição ética-política-cultural radical, em um movimento que sai da compreensão universalista hegemônica em direção a uma pluriversatilidade da terapia ocupacional. O sentido dessa proposição é favorecer processos de integração e solidariedade em nível mundial, por meio do reconhecimento e compreensão das histórias e realidades locais, que possibilitem "descolonizar a ocupação humana".

Recusar a singularidade do campo e buscar a qualquer preço se adequar à perspectiva dominante e dominadora de ciência criam um problema ético para as profissionais, e engendram um ambiente de acusação e desqualificação, como se as terapeutas ocupacionais não fossem capazes de articular sua competência ou as bases de suas posições.

A aproximação de epistemologias feministas pode ajudar a compreender e enfrentar as iniquidades de gênero que atravessam o 
tempo todo a vida das terapeutas ocupacionais, para que se possa reconhecer a oportunidade histórica de questionar radicalmente as bases do pensamento científico. Aqui, como em todos os campos de nossa cultura, as mulheres experimentam opressão em termos de desqualificação simbólica, desvantagens no acesso a recursos, menor poder de negociação, situações de humilhação e oportunidades limitadas de sair de situações abusivas ${ }^{\mathbf{2 4}}$. Em vários contextos e em várias partes do mundo, observa-se que, embora participem e tentem se envolver ativamente nas estruturas dominantes do poder masculino que operam nas universidades, nos serviços de saúde, e no contexto social, cultural e político mais amplo, as terapeutas ocupacionais são confrontadas cotidianamente com falta de oportunidades para o desenvolvimento pessoal e profissional ${ }^{22}$.

Além disso, não podemos ignorar que disciplinas e áreas acadêmicas se desenvolvem no interior de um sistema de saber e poder muito mais amplo que os campos particulares. $\mathrm{O}$ atual ambiente acadêmico em que vivemos, com estrangulamento de vários campos do saber, oferece, paradoxalmente, a possibilidade de que uma análise política da situação da terapia ocupacional floresça em novas alianças, no interior de trocas interdisciplinares, a partir das quais podem ser engendradas ferramentas conceituais para práticas em contextos e locais específicos, o que já vem acontecendo em algumas áreas de forma até promissora. Essas alianças podem apontar não só para o fim de atos predatórios contra qualquer forma de existência como também para a construção de modos de conhecer pautados em relações solidárias, nos quais as diferenças seriam expressões da vitalidade desejante do pensamento.

Se estamos diante de um quadro que agudiza de maneira extrema as consequências nefastas de um modo de organização social que fez surgir, no início do século XX, a terapia ocupacional, as práticas nesse campo podem se configurar em estratégias para o enfrentamento desse quadro. O componente anticapitalístico dessas práticas abre possibilidades de associações inusitadas entre a profissão e formas de resistência que têm sido esboçadas nos mais diversos recantos, na experimentação de diferentes modos de viver, de agir, de trabalhar e de pesquisar, e de novas formas de produção do comum e de ocupação do espaço público ${ }^{30}$.

Hoje, cada vez mais, as terapeutas ocupacionais têm reconhecido o importante componente político e ético de sua atuação profissional. Elas têm se colocado a responsabilidade de tornar a ocupação e a participação um direito humano fundamental - e isso não se restringe ao atendimento de pessoas e grupos específicos, mas se estende para o coração das comunidades às quais essas pessoas e grupos pertencem.

Para Kronenberg e colegas ${ }^{31}$, com seu foco na ocupação humana, a terapia ocupacional foi levada a enfrentar os problemas de desigualdade e se empenhar na promoção de princípios fundamentais, como o direito de todas as pessoas para construir seu próprio destino por intermédio da ocupação, ampliando a percepção do importante papel de fatores sociais, econômicos e políticos em melhorias significativas na saúde.

Há, atualmente, um movimento internacional na terapia ocupacional em direção ao engajamento político e à transformação social. Um grupo reunindo terapeutas ocupacionais de todo o mundo se agenciou em torno ao projeto 'Occupational Therapy Without Borders', e tem desenvolvido trabalhos no sentido de ampliar as oportunidades de engajamento em atividades relevantes e significativas entre imigrantes, sem teto, refugiados, comunidades em regiões devastadas pela guerra, e pessoas e comunidades em desvantagem, que vivem em situação de pobreza extrema ${ }^{32}$.

No Brasil, a terapia ocupacional tem expandido e fortalecido uma abordagem crítica da profissão, com preocupações sociais e engajamento político. Tais abordagens ultrapassam a perspectiva biomédica e o tratamento de 
patologias, dirigindo-se a um conjunto de preocupações relacionadas com desigualdades econômicas e sociais, com diferenças na proteção dos direitos humanos e com obstáculos para a ação e participação cultural e política, representando uma significativa alteração nos modos de pensar e agir no interior do campo ${ }^{\mathbf{2 8}}$.

Essas perspectivas que têm se fortalecido na profissão ressoam com o ativismo feminista presente em seu surgimento, alterando a forma de pensar a relação entre terapia ocupacional e política. Talvez se possa dizer que a terapia ocupacional não é somente uma profissão da área da saúde que, se necessário e em certas circunstâncias, adquire um significado político. A terapia ocupacional é política em si mesma, porque sua paisagem é a vida ativa e o mundo comum, isto é, a esfera política da vida humana que se desenvolve no espaço público ${ }^{33,34}$, no qual são introduzidas pessoas que foram alijadas dessa experiência por processos de exclusão e invalidação. No encontro com essas pessoas, operam-se desautomatizações da percepção, ampliam-se sensibilidades e exploram-se possibilidades de vida ainda insuspeitas. Pelo poder da ação, a terapia ocupacional toca essas regiões em que, segundo Espinosa, cada um pode encontrar a paz e a alegria nascidas da possibilidade de contemplar a si mesmo e sua própria potência de agir ${ }^{35}$.

\section{Fabricar as questões do presente}

A história de uma coisa, para Foucault, é a história da sucessão de forças que dela se apoderam, a variação de sentidos que ganha, a análise dos limites que lhe são postos e a pesquisa de sua ultrapassagem possível. Assim, ela é marcada por rupturas, continuidades, encobrimentos, desvelamentos e revelações e serve para pensar o presente ${ }^{36}$.

Criada durante a I Guerra Mundial, em um mundo que se desfazia, como uma das estratégias para sua recuperação, a terapia ocupacional foi trazida para o Brasil e para outros países da América Latina no período que sucedeu a II Guerra Mundial. Entretanto, o mundo que a profissão e seus profissionais encontraram aqui foi outro. A terapia ocupacional brasileira se desenvolveu em um contexto extremamente diferente da situação em que foi criada: aqui, já não havia um mundo a ser recuperado, e todo o desafio estava em construir e experimentar outros mundos, após as catástrofes que foram o massacre de povos originários das regiões que hoje compõem o País e a escravização de povos trazidos da África.

Não se trata, portanto, de buscar dar um solo teórico unitário e sólido a genealogias dispersas ${ }^{\mathbf{8}}$. Resgatar elementos para uma genealogia, descolonizá-los, valorizar e pôr em circulação esses elementos heterogêneos do campo da terapia ocupacional serve para afirmar uma herança, algo valioso que nos foi deixado, talvez sem testamento, e que nos cabe decifrar, significar e reativar ${ }^{37}$. Essa herança relaciona-se a uma tomada de posição: pôr-se em face do mundo na luta pelo 'direito a ter direitos' $\mathbf{3}$ para todas as pessoas - o que implica trazer para a arena política, da pesquisa e do pensamento, o cuidado e as formas de fazer e pensar que não coincidem com o modelo dominante do trabalho e da ciência. Essa herança tem sido reativada por terapeutas ocupacionais no Brasil e no mundo.

Há um interesse recente de terapeutas ocupacionais por questões conceituais e um movimento para se reconectarem com bases filosóficas e produzir uma prática indissociável do pensamento, o que tem levado a um renascimento das ideias presentes na origem da profissão ao mesmo tempo que se desenham linhas de fuga nos cenários da prática e no espaço da academia, a partir de uma visão particular de como se pode construir um conhecimento socialmente necessário e eticamente comprometido.

Nesse contexto, a perspectiva feminista tem contribuído sobremaneira. Testa \& Spampinato" ${ }^{11}$ insistem que ignorar as questões de gênero na profissão despolitiza a abordagem e invisibiliza as consequências das assimetrias 
de poder, constituídas por fatos, dispositivos, eventos e processos que se reproduzem socialmente e subjetivamente. Já Morison Jara $^{\mathbf{1 4}}$ aponta a importância de, no resgate da memória da terapia ocupacional, considerar as pesquisas que se concentraram na perspectiva feminista e na crítica das questões de gênero, já que o feminismo permite desnaturalizar práticas sistemáticas de injustiças e arbitrariedades que produzem sujeitos vulnerabilizados, e exercitar práticas de resistência.

Os exercícios de genealogia que foram aqui realizados contribuem para problematizar o fato de a maior parte das profissionais de terapia ocupacional serem mulheres, e de seu fazer estar marcado pelo lugar reservado às mulheres e ao feminino em nossa cultura, o que dá à profissão, ao mesmo tempo, menos poder e a potência do minoritário.

Assim, é possível vislumbrar a potência da terapia ocupacional para escapar às modelagens restritivas da vida e do trabalho no contemporâneo, justamente por seu desencaixe em relação aos modelos dominantes. Que desajustes acompanham essas mulheres, e hoje muitos homens também, que são tocadas por um desejo de diferença ${ }^{38}$ ? Mulheres empenhadas em cuidar de vidas e sujeitos historicamente invisibilizados, considerados insignificantes ou não inteligíveis; que buscam acompanhar pessoas que se movem em outras velocidades e lentidões para escapar, ao menos um pouco, de um mundo em aceleração; que não querem fortalecer uma forma de vida que já está em vias de se esgotar, esgotando consigo os corpos, as subjetividades e o mundo. Que lugar essa profissão extemporânea pode ter? Que escuridões pode fazer ver?

Ao afirmar o lugar de desajuste e extemporaneidade de nossa profissão em relação ao mundo que nos cerca e ao tempo que é o nosso, nós, terapeutas ocupacionais, poderemos, enfim, torná-la contemporânea - contemporânea de um desabamento do mundo moderno -, e assim ajudar a mapear o escuro do nosso tempo.

Para Giorgio Agamben ${ }^{39}$, o contemporâneo é o inatual, por meio do qual é possível tomar posição em face do presente. Aquele que pertence verdadeiramente a seu tempo, diz o filósofo, é aquele que não coincide perfeitamente com ele; e, por isso, está mais apto que os outros para perceber seu próprio tempo. Ser contemporâneo é fixar o olhar sobre seu tempo, para perceber não somente as luzes, mas também a escuridão.

\section{Colaboradora}

Lima EMFA (0000-0003-0590-620X)* é responsável pela elaboração do manuscrito. 


\section{Referências}

1. Gutman S. Influence of the U.S. Military and Occupational Therapy Reconstruction Aides in World War I on the Development of Occupational Therapy. Am. J. Occup. Ther. 1995; 49(3):256-262.

2. Galvão AP, Cocco G, Silva G, organizadores. Capitalismo cognitivo: trabalho, redes e inovação. Rio de Janeiro: DP\&A; 2003.

3. Arendt H. Origens do Totalitarismo. São Paulo: Cia das Letras; 2012.

4. Butler J. Quadros de guerra: quando a vida é passível de luto? Rio de Janeiro: Civilização Brasileira; 2015.

5. Agamben G. Homo Sacer I: o poder soberano e a vida nua. Belo Horizonte: Ed. da UFMG; 2002.

6. Benetton MJ. Trilhas Associativas: ampliando recursos na clínica da psicose. São Paulo: Lemos; 1991.

7. Wilcock AA. An Occupational Perspective of Health. Thorofare: Slack Inc.; 1998.

8. Foucault M. Em defesa da Sociedade. Curso no Collège de France (1975-1976). São Paulo: Martins Fontes; 1999.

9. Vogel B, Benetton J, Goubert J-P. Terapia ocupacional - história de uma profissão feminina. Rer. Cent. Est. Ter. Oc. 2002; 7(7):38-42.

10. Figueiredo MO, Zambulim MC, Emmel MLG, et al. Terapia ocupacional: uma profissão relacionada ao feminino. Hist. cienc. saúde-Manguinhos. 2018; 25(1):115126.

11. Testa DE, Spampinato SB. Género, salud mental y terapia ocupacional: algunas reflexiones sobre la influencia de la historia de las mujeres y la perspectiva de género en nuestras prácticas. Rev. Ter. Ocup. Univ. São Paulo. 2010; 21(2):174-181.

12. Frank G. Opening feminist histories of Occupational Therapy. Am. J. Occup. Ther. 1992; 46(11):989-999.
13. Hamlin R. Embracing our past, informing our future: a feminist re-vision of health care. Am. J. Occup. Ther. 1992; 46(11):1028-1035.

14. Morrison Jara R. Feminismo(s) y Terapia Ocupacional. Preguntas y reflexiones. Rev. Arg. Ter. Ocup. 2018; 4(2):60-72.

15. Frank G, Zemke R. Occupational therapy foundations for political engagement and social transformation. In: Pollard N, Sakelariou D, Kronenberg F. A political Practice of Occupational Therapy. Londres: Churchill Linvingstone; 2009. p. 111-136.

16. Hamington M. Jane Addams. In: Zalta E, editor. Stanford Encyclopedia of Philosophy. Stanford: Stanford University; 2006. [acesso em 2020 mar 5]. Disponível em: http://plato.stanford.edu/entries/addams-jane/ index.html.

17. Encyclopidia of Chicago. Hull House. [verbete]. [acesso em 2020 mar 5]. Disponível em: http://www. encyclopedia.chicagohistory.org/pages/615.html.

18. Breines E. Pragmatism as a Foundation for Occupational Therapy Curricula. Am. J. Occup. Ther. 1987; 41(8):522-525.

19. Almeida MVM, Costa MC. Movimento de artes e ofícios: perspectiva ética-política-estética de constituição da Terapia Ocupacional. In: Silva CR, organizador. Atividades Humanas e Terapia Ocupacional: saber-fazer, cultura, política e outras resistências. São Paulo: Hucitec; 2019. p. 59-79.

20. Pilan FC. Consciência, pensamento e ação no pragmatismo de William James. Problemata Rev. Intern. Filos. 2014; 5(2):274-284.

21. Morrison Jara R. Los comienzos de la terapia ocupacional en Estados Unidos: una perspectiva feminista desde los estudios de Ciencia, Tecnología y Género (siglos XIX y XX). Hist. Crit. 2016; 62(1): 97-117.

22. Sakelarious D, Pollard N. Three sites of conflict and 
cooperation: class, gender and sexuality. In: Pollard N, Sakelariou D, Kronenberg F. A political Practice of Occupational Therapy. Londres: Churchill Linvingstone, 2009. p. 69-90.

23. Melo DOCV. Em Busca de um Ethos: Narrativas da Fundação da Terapia Ocupacional na Cidade de São Paulo (1956-1969). [dissertação]. [São Paulo]: Universidade Federal de São Paulo; 2015. 122 p.

24. Braidotti R, Charkiewicz E, Häusler S, et al. Mulher, ambiente e desenvolvimento sustentável. Lisboa: Instituto Piaget; 1994.

25. Collins PH. The Social Construction of Black Feminist Thought. Signs. 1989; 14(4):745-773.

26. Haraway D. Saberes localizados: a questão da ciência para o feminismo e o privilégio da perspectiva parcial. Cad. Pagu. 1995; (5):7-41.

27. Haraway D. A partilha do sofrimento. Horiz. Antrop. 2011; 17(35):27-64.

28. Galheigo SM. What needs to be done? Occupational therapy responsibilities and challenges regarding human rights. Aust. Occup. Ther. J. 2011; 58(2):60-6.

29. Morán JP, Ulloa F. Perspectiva crítica desde Latinoamérica: desobediencia epistémica en terapia ocupacional contemporánea. Cad. Ter. Ocup. UFSCar. 2016; 24(2):421-427.

30. Aleixo JMP, Lima EMFA. Invenção e produção de encontros no território da diversidade: cartografia de um Centro de Convivência. Cad. Ter. Ocup. UFSCar. 2017; 25(3):649-659.
31. Kronenberg F, Fransen H, Pollard N. The WFOT Position Paper on Community-based Rehabilitation: A Call upon the Profession to Engage with People Affected by Occupational Apartheid. World Fed. Occup. Ther. Bull. 2005; 51(1):5-13

32. Kronenberg F, Algado SS, Pollard N, editores. Occupational Therapy without Borders. Oxford: Elsevier; Churchill Livingstone; 2005.

33. Arendt H. A condição humana. Rio de Janeiro: Forense Universitária; 2003.

34. Lima EMFA. Vida ativa, mundo comum, políticas e resistências: pensar a terapia ocupacional com Hannah Arendt. São Paulo: FMUSP; 2017.

35. Agamben G. Arte, Inoperatividade, Política. Crítica do contemporâneo - Conferências Internacionais Serralves. Lisboa: Fundação de Serralves; 2007.

36. Deleuze G. Foucault. São Paulo: Brasiliense; 1991.

37. Arendt H. Entre o passado e o futuro. São Paulo: Perspectiva; 2014.

38. Lima EMFA. Desejando a diferença: considerações acerca das relações entre os terapeutas ocupacionais e as populações tradicionalmente atendidas por estes profissionais. Rev. Ter. Ocup. USP. 2003; 14(2):64-71.

39. Agamben G. O que é o contemporâneo? e outros ensaios. Chapecó: Argos; 2009.

Recebido em 31/08/2020

Aprovado em 28/06/2021

Conflito de interesses: inexistente

Suporte financeiro: não houve 